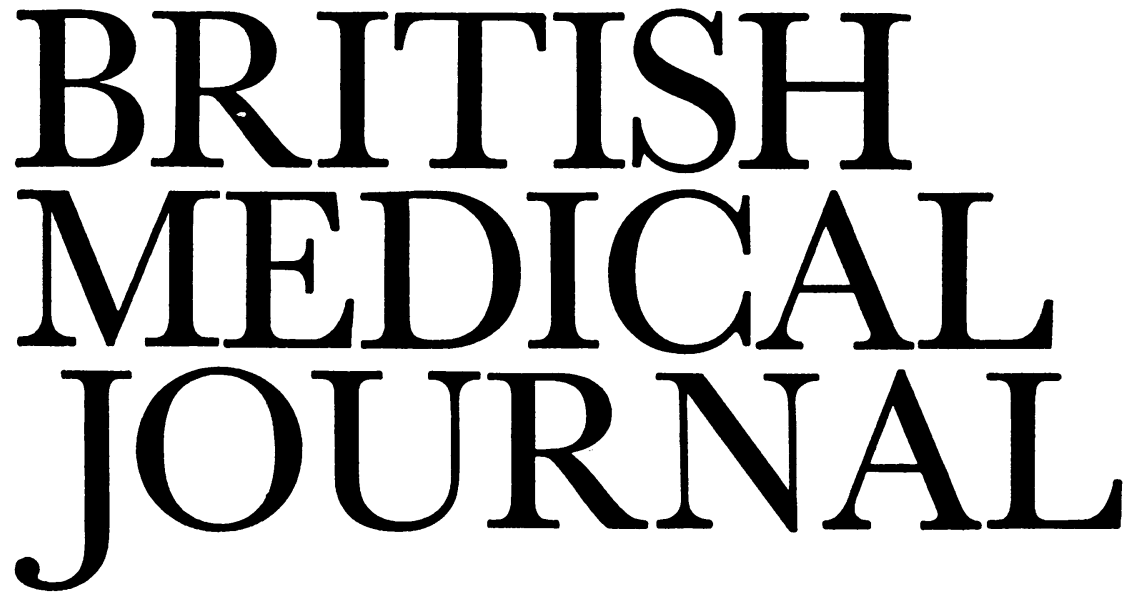

\title{
Crohn's Disease of the Large Bowel
}

Differentiation between ulcerative colitis and Crohn's disease of the large intestine can be made in many cases on clinical, radiological, and pathological criteria, though some cases remain difficult to classify. Clinical features suggestive of Crohn's disease are the comparative absence of rectal bleeding, high frequency of perianal disease, and often the normal appearance of the rectum on sigmoidscopy. The barium enema examination may show patchy disease of the colon, perhaps with areas of stricture formation. Mucosal cobble-stoning, ulceration, and fissuring may produce a typical appearance, in contrast to the fine diffuse mucosal ulcers in colitis. A barium follow-through examination may show associated lesions in the small intestine.

Pathologically Crohn's disease is characterized by a cobblestone mucosa with irregular linear ulcers separated by areas of almost normal mucosa. Histologically there may be one or more of the following criteria: tuberculoid granulomata, intramural abscesses, and transmural or serosal inflammation. Internal fistulae to adjacent organs may be associated with Crohn's disease but are not seen in ulcerative colitis. Toxic dilation does not occur, and both perforation and malignant change, though reported, are much rarer than in ulcerative colitis. ${ }^{2-4}$

It is well known that Crohn's disease of the small intestine tends to recur, either at the region of the resection itself or elsewhere in the bowel, in a high proportion of cases, amounting to something like $50 \%$ of the patients five to ten years after operation. ${ }^{5-6}$ Crohn's disease of the colon has a similar tendency to recurrence after surgery as well as the development of further perianal disease, which renders the management of this condition far from simple. Some years ago it was suggested that the disease might be treated by a preliminary double-barrelled ileostomy to defunction the large bowel, to enable topical steroids to be given, and to allow conservative resection of strictures to be performed. ${ }^{7}$ H. A. Oberhelman and his colleagues ${ }^{8}$ carried out this procedure on 13 cases of Crohn's disease of the colon. All showed excellent response and three subsequently underwent restoration of continuity of the bowel, with a minor flare-up of the disease in one case. However, J. H. Burman and his colleagues, 9 though finding that 23 out of 24 of their patients undergoing this procedure showed improvement in general health, noted that 12 patients who had subsequent resection all showed evidence of continued disease in the defunctioned segment, and they conclude that there is little chance of "resting" Crohn's disease in the expectation of restoring the bowel to normal.

If the disease is confined to the right side of the colon, then conservative resection is carried out, but this may entail sacrifice of a considerable segment of the diseased ileum. When there is extensive disease of the whole of the large bowel, including the rectum, unresponsive to conservative treatment, there appears to be no alternative but total colectomy with permanent ileostomy. Unlike patients with ulcerative colitis, who can at least be guaranteed freedom from recurrence of their disease after undergoing this operation, a patient with extensive Crohn's disease of the colon who undergoes total colectomy is still at risk of ileal recurrence. W. A. Hawk and R. B. Turnbull ${ }^{10}$ report this in $20 \%$ of their patients (17 out of 87 proctocolectomies).

When the rectum is comparatively healthy and there is extensive disease of the rest of the colon most surgeons carry out resection with ileorectal anastomosis. A number of recent reports give some indication of the prognosis after this procedure. W. N. W. Baker ${ }^{11}$ studied 26 patients undergoing ileorectal anastomosis at St. Mark's Hospital, London, for Crohn's disease of the colon. There was one postoperative death, one leakage requiring excision of the rectum with ileostomy, and five patients who developed progressive disease from which they either died or required subsequent excision of the rectum and ileostomy. There were three later unrelated deaths, and only four of the patients were found to be free from recurrence of disease at subsequent follow-up. Usually the disease recurred in the region of the ileorectal anastomosis, but three patients developed ileal disease as well as anastomotic recurrence, and one developed an ileal lesion without anastomotic recurrence. Compared with ulcerative colitis treated by ileorectal anastomosis, the Crohn's disease series gave a lower initial mortality and morbidity but the long-term prognosis was worse. However, Baker points out that recurrent disease was often controlled by sulphonamides and steroids, so that further surgery might not prove necessary.

Burman and his colleagues, 12 from the General Hospital, 
Birmingham, reviewed 25 patients who had undergone this operation. In eight cases there were postoperative leakages of the anastomosis, with one death, and these occurred even in the presence of a safety-valve ileostomy. Two other patients in the series died and 10 required further resection, four having a new anastomosis performed and the rest having an ileostomy. Of the whole group, $10(40 \%)$ ultimately had a successful ileorectal anastomosis, two of these after a second resection of the recurrence. Since recurrence may also follow proctocolectomy, these authors consider that the ileorectal anastomosis remains a suitable procedure for Crohn's disease of the large bowel.

F. T. de Dombal and his colleagues ${ }^{13}$ from Leeds found that recurrence after surgery is particularly likely in children affected with Crohn's disease, and the percentage of recurrence drops with increasing age. B. I. Korelitz ${ }^{14}$ has also pointed out the gloomy prognosis when the disease affects the large bowel with onset in childhood. Recurrence is more likely to follow resections of small intestine $(40.4 \%)$ than of large intestine $(11.8 \%)$, but interestingly enough when both the large and small intestine were involved the recurrence rate was the same as in cases affecting the small intestine only. The recurrence was usually in the small intestine proximal to the anastomosis and was usually either in the period one to two years after operation or in the period five to fifteen years after it; the outlook was graver in the former group. Of the patients with recurrences, one-third were managed conservatively, and those undergoing a second operation were found not to have a higher risk of requiring further surgery than patients undergoing a primary operation. At review some $70 \%$ of the patients with a recurrence were in good or very good health, and about three-quarters were satisfied with the outcome of treatment.

\footnotetext{
1 Farmer, R. G., Hawk, W. A., and Turnbull, R. B. American Fournal of Digestive Diseases, 1968, 13, 501.

2 Kyle, J., Caridis, T., Duncan, T., and Ewen, S. W. B., American fournal

of Digestive Diseases, 1968, 13, 275 .
Midgley, F. M., and Thompson, N. W., Archives of Surgery, 1968, 97, 553.

- Perrett, A. D., Truelove, S. C., and Massarella, G. R., British Medical Fournal, 1968, 2, 466

5 Atwell, J. D., Duthie, H. L., and Goligher, J. C., British fournal of Surgery, 1965, 52, 966.

- Lennard-Jones, J. E., Gut, 1967, 8, 332.

7 Truelove, S. C., Ellis, H., and Webster, C. V., British Medical Fournal, $1965,1,150$

Oberhelman, H. A., Kohatsu, S., Taylor, K. B., and Kivel, R. M., American fournal of Surgery, 1968, 115, 231.

- Burman, J. H., Williams, J. A., Thompson, H., and Cooke, W. T., Gut, $1969,10,1054$.

${ }^{10}$ Hawk, W. A., and Turnbull, R. B., Gastroenterology, 1966, 51, 802.

1 Baker, W. N. W., Gut, 1971, 12, 427.

12 Burman, J. H., Cooke, W. T., and Williams, J. A., Gut, 1971, 12, 432.

13 Dombal, F. T. de, Burton, I., and Goligher, J. C., Gut, 1971, 12, 519.

14 Korelitz, B. I., Fournal of the Mount Sinai Hospital, 1968, 35, I.
}

\section{Iodine-125 in Hyperthyroidism}

Iodine- 125 has a half-life of 60 days compared with the eight days of ${ }^{131} \mathrm{I}$, conventionally used in the treatment of hyperthyroidism. Its radiation is largely of low energy electrons with a shorter range than the radiation from ${ }^{131} \mathbf{I}$, and its radiobiological effects will therefore be concentrated on the apex of the thyroid cell adjacent to the colloid where iodine is stored. On the other hand, the nucleus, which is asymmetrically situated nearer the base of the thyroid cell, will receive less radiation. ${ }^{1}$ The higher-energy, longer-range radiation of ${ }^{131}{ }^{13}$ radiates the thyroid cell uniformly.

Postradiation hypothyrodism, the major complication of radioiodine therapy, results primarily from radiation damage to cell nuclei, which cease to divide. ${ }^{2}$ The physical properties of ${ }^{125}$ I make it an attractive theoretical tool to reduce radiation to the nuclei while providing a higher dose of radiation to the apex of the thyroid cell which is active in hormone synthesis. Possibly ${ }^{125} \mathrm{I}$ in doses equivalent to ${ }^{131}$ I has less effect on thyroid growth, presumably because of reduced nuclear damage. ${ }^{3}$ However, proponents of ${ }^{131} \mathrm{I}$ would argue that a reduction in the dose of this isotope would have the same effect. ${ }^{4}$

Reducing the dose of 131I lowers the incidence of hypothyroidism but it controls hyperthyroidism more slowly and most patients need antithyroid drugs in addition, though usually for less than two years. ${ }^{4}$ With similar nuclear doses, and hence similar hypothyroidism rates, ${ }^{125}$ I has been claimed to be preferable to ${ }^{131}$ I because it controls symptoms more rapidly and thus antithyroid drugs are not required. But it is impossible to be precise in radioiodine dosimetry because of the many variables. The more rapid control of hyperthyroidism by ${ }^{125}$ I has been thought to be due to its greater effect on the "hormonogenetic" parts of the thyroid cell than on the nucleus. ${ }^{5}$ In man evidence for this is lacking, but in animals there is some support for a relative dissociation of the effects of 125 I on hormone production and growth potential. 6 A lower dose of radiation to thyroid nuclei might be disadvantageous. Nuclear damage without destruction in association with thyrotrophin stimulation in response to thyroid failure is certainly carcinogenic in animals. It is now well established ${ }^{131} \mathrm{I}$ is not carcinogenic.

The effects of ${ }^{125}$ I therapy in terms of the rate of control of hyperthyroidism and of the long-term incidence of hypothyroidism and thyroid neoplasia need to be established. Until then W. R. Greig and his colleagues 5 are probably right to advocate that this isotope should be used only in special centres with facilities for long-term follow-up.

${ }^{1}$ Gillespie, F. C., Orr, J. S., and Greig, W. R., British fournal of Radiology, $1970,43,40$.

2 Al-Hindawi, A. Y., and Wilson, G. M., Clinical Science, 1965, 28, 555.

Greig, W. R., Smith, J. F. B., Orr, J. S., and Foster, C. J., British fournal of Radiology, 1970, 43, 542 .

4 Smith, R. N., and Wilson, G. M., British Medical fournal, 1967, 1, 129.

${ }^{5}$ McDougall, I. R., Greig, W. R., and Gillespie, F. C., New England Fournal of Medicine, 1971, 285, 1099.

- Gross, J., Ben-Porath, M., Rosin, A., and Bloch, M., in Thyroid Neoplasia, ed. S. Young and D. R. Inman, p. 291. London, Academic Press, 1968.

${ }^{7}$ McDougall, I. R., Kennedy, J. S., and Thomson, J. A., fournal of Clinical Endocrinology and Metabolism, 1971, 33, 287.

\section{The Queen's Shilling}

What makes a man take the Queen's shilling? The reasons are probably as numerous as the number of recruits to H.M. Forces. But attracting doctors into the Forces calls for rather more than glossy television advertisements extolling the excitement, glamour, travel, and good pay in service life. For nearly 18 years after the second world war National Service supplied the doctors needed by the armed Forces. However, conscription ceased in 1960 and the Government then found it necessary to offer a real incentive to attract doctors into the Forces. The B.M.A. co-operated with the Government in tackling the situation and the "new deal" 